\title{
SCC Failure in Vent System on Radioactive Waste Storage Tank
}

\author{
C.F. Jenkins
}

SRNL, Westinghouse Savannah River Company, Aiken, SC 29808, USA

Several cracks were discovered in a fabricated galvanized steel duct of the vapor purge discharge system on top of a high level radioactive waste storage tank. The cracks were found beneath thermal insulation during upgrading of the exhaust flow monitoring system. The exhaust is filtered upstream of the failed vent and is not contaminated. The exhaust fans are downstream.

All of the observed cracks have a circumferential orientation and developed from inside. The cracks occur in the heat affected zones of both seam and girth welds. The entire vent assembly was provided for study to determine contributions of corrosion, stress corrosion, fatigue, etc. to the cracking. Liquid metal embrittlement related to zinc was also considered.

The internal wall of the tubing had spotty general rusting and heavily rusted tracks along the fieldmade seam and girth welds. A white deposit covered most of the inner wall beyond the tracking, and penetrated to the external surfaces at the cracks. The white substance contained was made up primarily of zinc and iron oxide/hydroxide compounds. The structural results suggested that nitrates also may be entrained in the vapors.

Close examination of crack areas on cut sections and polished metallographic samples indicated no presence of $\mathrm{Zn}$. The x-ray results from the SEM showed zinc was not entrained in the weld. Thus, liquid metal embrittlement was eliminated as an explanation for the cracks.

One very large crack midway in the assembly nearly divided the assembly in two. A $1 / 8$ inch separation existed at a girth weld joining two straight lengths of pipe. The break actually consists of multiple cracks at a toe of the weld, and the parallels the weld in the fusion and heat affected zones. A similar break with less separation or parting occurred in a girth weld at a fabricated reducer.

In addition to two cracks at girth welds, there were six cracks on axial seam welds along the pipe. All were oriented circumferentially, were $~ 2.5$ inches long, and had nearly equal lengths on each side of the seam weld. The crack lengths are mostly within the rust resistant paint strip on the outer surface, but all the cracks extend well beyond the anticipated HAZ - 1 to 3x sheet thickness [1].

Study of the fractured surfaces in the SEM did not reveal any peculiarities at the crack origins, though the cracks did initiate in the HAZ. No striations related to fatigue were observed. A macroshading phenomenon on the fractures suggests large step crack growth from inside to outside across the thickness. The fractured surfaces had been exposed in chemical baths designed to remove rust. Some longer exposures could possibly have affected this shading.

Evidence of IGA in the fracture is seen in the SEM work, but stress definitely plays a role and IGSCC is possible. There are a limited number of chemical species that may lead to the effect in carbon steel, including nitrate and hydroxide. These are principal constituents of the waste in the tanks, and they are present in the vapor space above the bulk solution. Slight corrosion occurs in the 
tank [2], but vapors are unexpected in the vent system. Cyclical variation in humidity together with entrained ions provide a means for developing the concentrate and salt deposits in the vent system.

Residual stresses in the pipe due to weld shrinkage result in tensile loading in the axial direction within the weld zone of the seams. Moreover, the residual tensile stress and mechanical drive for cracking at the girth joints is also axially oriented, as a result of axial constraints in the fabrication process. The large gap occurring at the center girth joint indicates prior existence of a very large strain and stress, related to fit up between the fixed flange locations on the tank. The direction of crack growth is driven by those residual stresses.

\section{References}

1. Welding Handbook, "Fundamentals of Welding", v 1, 7th ed., AWS, 1981, p 81-85.

2. Subramanian, K. H., Zapp, P. E., "Vapor Space and Liquid/Air Interface Corrosion Tests of Low Carbon Steel," WSRC-TR-2002-00471, November 2002.

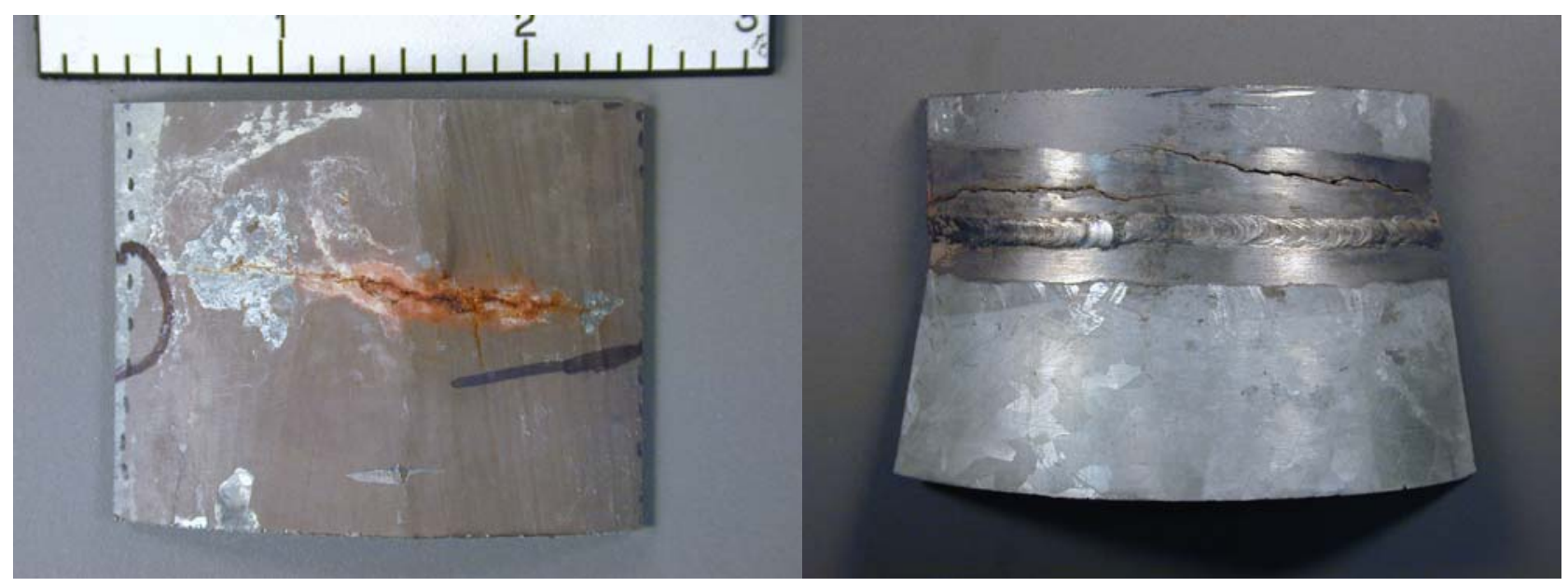

Fig. 1. Sections of pipe from vent system on waste tank. Cracks are in heat affected zones of welds.

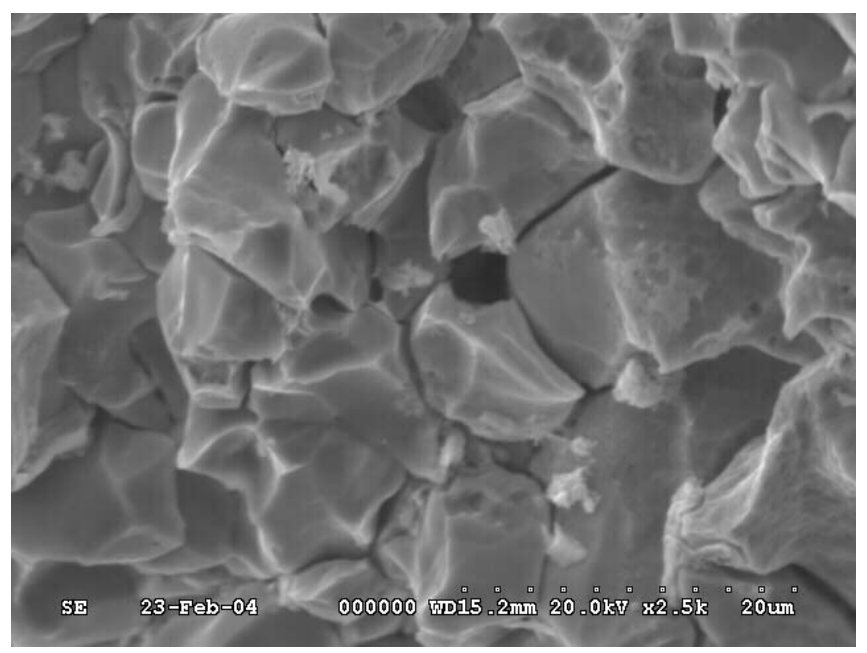

Fig. 2. IGA in fracture of seam weld on steel pipe. 